\title{
History integrated urban transformation
}

\author{
W. van der Toorn Vrijthoff \\ Delft University of Technology, Faculty of Architecture, \\ Department of Real Estate and Project Management, Delft, \\ The Netherlands
}

\begin{abstract}
The economic growth and the growth of the European urban area was at a particularly high level in the second half of the twentieth century. The public and economic functions, traditionally located in the inner cities, needed more and more space during that period and were re-located. They moved to bigger buildings on more reachable sites, outside the inner cities. At the same time the mobility of people improved steadily and cities increasingly had to compete for the favour of the consumer. "City branding" became a common term in those days. With this in mind, the specific identity of the city is of crucial importance. The area of the old inner city is essential in that context, but in the way it was and not the way it has become. The historic embedded identity forms the counterpoint for the dominant influence of a levelling global culture. The faster society is changing, the more attention for the stability of history, the more popular is the preservation of cultural heritage. On the basis of that, in many European cities plans are made or carried out to restore and maintain cultural heritage in combination with renewal, all integrated in transformation plans for parts of the inner city. The decision process about inner city transformations is based on the economic interests of private as well as local public participants. The costs of restoration of cultural heritage are covered by public and private funds. The historic inner city has gained a unique status and "cultural heritage became business".

This research goes explores how and why cultural heritage has gained importance for any city in Europe and considers how that importance can be integrated in profit based urban transformation projects, projects in which the private sector becomes more and more important.
\end{abstract}

Keywords: urban transformation, cultural heritage, historic inner city, authenticity, conservation, preservation. 


\section{The historic inner city, definition and specification}

The historic inner city is a territorial concept, in contrast with the city centre which is defined in a functional sense. Two definitions of the historic inner city tell the same story:

"The city area that already was there before the period of urban growth in the second half of the nineteenth century and for the most of it bounded by canals". (van Duren 1995)

"That part of the city that was situated within the last constructed defensive wall, which wall was demolished during the nineteenth century, in order to facilitate the strongly increased city population and enable the necessary urban growth". (Schuiling, e.a., Functionele vernieuwing van Binnensteden 1960-1990). About $2 \%$ of the actual urban area is taken by the area that we see as the historic inner city.

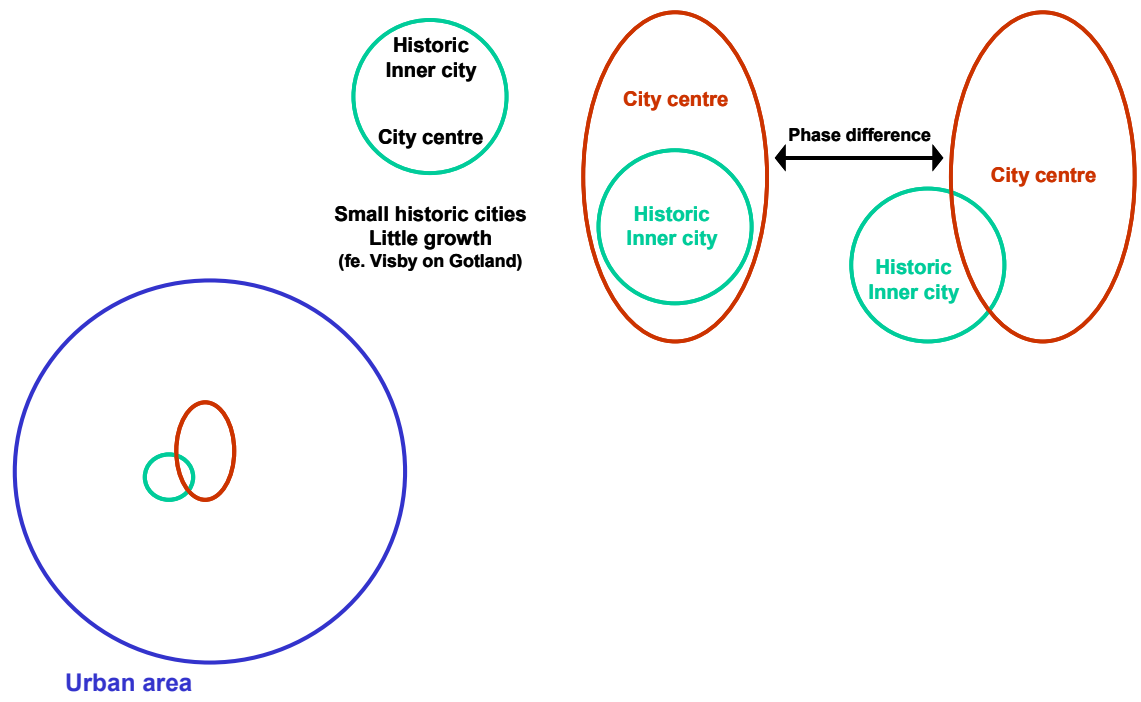

Figure 1: $\quad$ Historic inner city, city center and urban area.

Any discussion of the historic inner city is inevitably also a discussion about cultural heritage. The definition for cultural heritage of Turnbridge is attractive because it is simple.

"Heritage is that which we have inherited from the past." [6, page 236]

That definition refers to heritage and not specifically to cultural heritage. However, any heritage always has cultural roots. If we use the definition of Turnbridge for cultural heritage then there is no selection criterion. European societies definitely make a selection in their judgment of what part of our heritage should be seen as cultural and what should not. For example, the Dutch government is using the following criteria: 
- Rarity

- Undamaged

- Representative.

This criteria leads to the result that the historic inner cities of Europe become the places to be careful with, because of the fact that it is there that most of our urban cultural heritage is to be found

\section{Position and profile of the historic inner city: past and present}

The Industrial Revolution triggered off a considerable increase of urban areas in Europe. After the Second World War, this development changed at an accelerating pace. The postwar baby boom was followed by a growing trend towards smaller family sizes and an increase in the use of space by individuals. The precondition for these developments was the steady economic growth in Europe.

Growth took place in all sectors, bringing with it an increase in spatial scale. Consumer spending continued to grow within the framework of favorable economic developments. These developments were accompanied with a need for space for which the historic city centre did not have sufficient potential. As a result, functions moved to other premises. More space and better accessibility were the key motives for choosing locations other than the historic centre.

The finely woven spatial structure of the historic centre combined with a wide differentiation in types of ownership makes it either difficult or impossible to fit in large-scale functions without affecting the centers spatial quality.

The first reaction to the exodus of commercial activity concentrated on modifying the spatial structures with the aim of adapting the historic centre to the requirements of the time. The changes were particularly rigorous in the United States. Jane Jacobs reacted to that development, noting that the unique qualities of old city centres were being rapidly effaced. Europe was following the example of America with a certain delay and, fortunately, not quite as comprehensively. It soon became clear that the suburbanization of economic life could not be stopped by a metamorphosis of the urban spatial structures. A separation of economic interests took place, and the historic centre changed from being a place of production into a place of consumption.

A repetition of this process is now imminent. For years, the geographical centre of gravity for consumer expenditure has been located in the city centre. This is now changing because the growth of consumer expenditure is accompanied by a substantial increase in spatial requirements. A self-evident, but not sensible, reaction to this trend is a far-reaching reorganization of the city centre so as to create more space (figure 2) The probability of destroying the unique spatial quality of the old centre is high, and the centre is likely to become a poor alternative to more accessible and more spacious locations.

The relative market positions of individual distinct urban areas are subject to constant change. The evolving market position of the historic city centre can be ascribed to the following developments and aspects: 


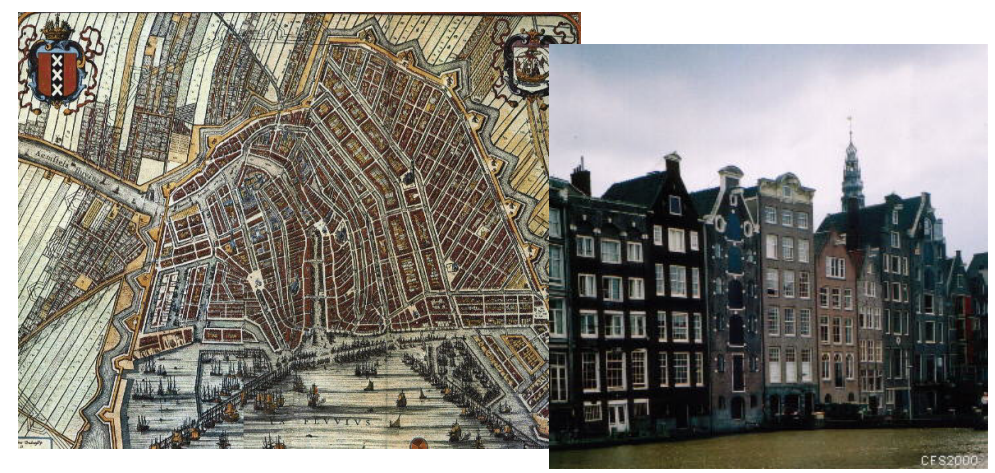

Figure 2: The map of Amsterdam $17^{\text {th }}$ century and a view on some old attractive houses.

The original users are transferring their activities to other locations, while new users present themselves. The motives of those departing are related to aspects such as accessibility, spatial capacity and price.

- Relative functional obsolescence: technology is developing quickly and continually generates new 'tools' for industry and consumers. Developments in ICT illustrate this trend well. The historic city centre adapts with much greater difficulty to the demands of present times (particularly when large-scale modifications are involved) compared to other city areas.

- Demographic developments: population growth induces expansion within existing cities. The territory and population size of the city as a whole increase, while the land area of the historic centre remains constant and thus 'shrinks' in relative terms.

- The technical ageing of buildings, due to among other things intensive use.

- The increasing 'rarity value' of the historic inner city, which exerts a positive effect on its attractiveness and market position.

- The growing action radius of companies and consumers. The number of locations which may be considered in the selection process by companies and individuals has undergone tremendous growth. Companies are becoming increasingly global in outlook, and the European scale is becoming an everyday reality for individual consumers.

In Europe we have been through a lengthy period - to be expressed in centuries - during which progressive urbanization has been the norm. The industrial period, in particular, saw unprecedented growth in the size of cities. During Europe's post-war development phase, the main basic assumption was one of continuing urbanization, with the result that the level of urbanization currently stands at $80 \%$.

Relatively speaking, the old centre has been shrinking continually. This development will continue in the coming years. Changes attuned to creating 
more space will prove insufficient. The status and market position of the centre will change nonetheless.

Within the service economy, the historic city centre is regaining a position in the focus of social developments. In "The future of the center: The core City in the new economy" by Joel Kotkin [3], the author sketches future economic developments, with the historic centre playing a key part in them.

"Even under the best of circumstances, center cities are unlikely to ever emerge as the geographically dominant centers of their metropolitan regions as they were in the industrial era. Instead, the new urban core resembles more that of the renaissance city- relatively smaller, and built around classical urban functions such as arts, cross-cultural trade, and highly specialized small-scale production" "Ultimately, the revival of the urban core, whether in the traditional city or the more dispersed model common to the sunbelt agglomerations, stems from a search for a sense of place and history amidst a society in which the barriers of time and space are under constant assault. As centres of arts and culture, repositories of our past history and architecture, the core retains a powerful tug of consciousness. It reminds us not only who we are but also what we have been".

\section{Strategies for modifications}

The continually fluctuating market position of individual city areas is reflected in changes to their status and function. These changes are in turn a spur to spatial modifications. It is more complex to modify an existing urban area than to develop a greenfield site, because the developers cannot start from a 'virgin ground' situation. The kind of areas referred to here are those whose potential exceeds the level of current use. This means that there is scope for investments aimed at improving the physical environment - changes that contribute to a balance between the market position of the location, the urban area, and the function and status of the properties located there. If the discrepancy between the present use and the changed situation is only a small one, it will often suffice to adapt the existing buildings only. In other cases, the market situation gives greater leeway, making it possible to consider alternatives such as demolition and construction of new buildings. This kind of development is often accompanied by an expansion of the overall building volume and an increased building density. In its most extreme form, the urban structure may itself be modified.

The general rule that changing function and status are followed by spatial changes does not apply to the historic inner city. The spatial characteristics of the centre are stable in character. This is largely related to the complexity of the spatial changes. Changes in other urban areas and extensions to the total city area are vastly simpler to carry out; investments in outer areas carry less risk and are therefore more attractive to developers. The high level of risk puts a brake on improvements to inner city locations. The relative market position of the historic centre is changing rapidly precisely because, from a spatial viewpoint, much stays the same. 


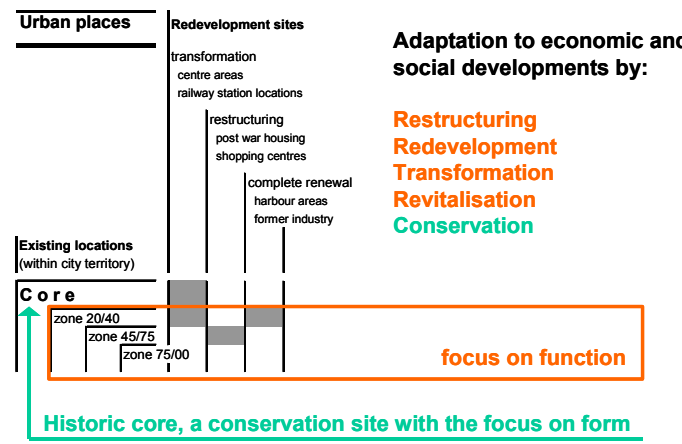

Figure 3: The historic core, a conservation site.

The spatial stability of the city centre is not only a result of the complexity of change. The urban structure and the buildings within that structure were realized in an era when the building industry was organized into guilds. The patrons who ordered the construction of many of the buildings in the historic centre were church communities or wealthy burghers. The levels of craftsmanship achieved would be almost impossible to match today. These qualities have resulted in a unique spatial ensemble which imposes restraint on anyone planning to initiate spatial improvements.

If a similar spatial inertia prevailed in another part of the city, its market position would deteriorate rapidly. It would run the risk of decay and impoverishment. Changes in the functional demands placed on the buildings and the urban environment in these areas have to be followed closely by spatial and technical adaptations. The historic centre forms an exception to this rule.

The historic structures and buildings are a communal good which is not open to discussion. Both companies and individuals are keen to take advantage of the available spatial facilities. As Joel Kotkin [3] points out, the companies concerned are mainly small-scale enterprises which are offshoots of the new economy.

This trend is largely explained by the specific identity of the historic centre. 'Identity', according to Paul Meurs [1, page 269], is that quality that transforms an arbitrary location into a specific place. He cites the anonymous suburbs as exemplifying places where there is a total lack of identity. He is partly correct. However, those who grow up in suburbs, which others see as monotonous, do perceive a local identity. It is made up of personal experiences that have a direct relationship to the location - not so much objective spatial characteristics as individual experiences evoked by the place.

The increasing mobility of the native European population and the increasing number of non-native Europeans has caused a dislocation between spatial identity and the individual experience. Yet there is a primary need for spatial landmarks within the experiential world. The city centre has an important function in this respect. It serves as an emblem for the modern city that has 
developed around it. The modern, dislocated European seeks terra firma in the historic inner city. The monotony of the urban expansion areas of the last century, particularly those dating from the period following the Second World War, engenders psychological disorientation.

The historic city centre thus has an important communal function. The extent to which that function can be adequately fulfilled in the future depends strongly on how the renewals, which must inevitably take place, will be implemented. The worst mistake - one that can be fatal to the qualities of the historic centre is to approach the inner city with the same strategy as other urban areas.

The spatial modifications in the historic inner city have to be made with respect for the smallness of scale of buildings and the "finely woven" urban structure. During the execution of any modification made, the historic inner city stays in function, and that makes it complicated. It is like tinkering on a running engine. The spatial modifications can be related to preservation, restoration and renewal applied to parts of buildings, buildings, public space and urban infrastructure.

Decision making implicating the balance between preservation, restoration and renewal (preservation and innovation) can be structured by the following questions:

- Why save it, why modify it?

- What to save or modify?

- How to do it, regarding the aspect of authenticity.

Those questions can be approached from different points of view like:

- Philosophical approach

- Economical approach

- Social

- Functional.

In the following paragraphs the accent will be laid on the philosophical approach.

\section{Why save it, why change it?}

"In western society people live longer and because of growing mobility they remain seldom surrounded by the things and the house they grew up with. Therefore they stick to the last remaining recognizable things; the changing surroundings is compensated by an increased interest for history." [4]

The same message as Lowenthal is given, nearly twenty years later, in a policy document of the central government of the Netherlands [7]. The following statement is made in that document:

"The need for historical embedded identity, for slow movement in time, for distinction ability, for nuances, familiar situations and variety, can also be seen as the counter point for the dominant influence of the levelling global culture. Handling the cultural heritage with respect guarantees the historical continuity and opens up possibilities to preserve the cultural identity of a village, city, region and even the whole country." [7, page 11] 
Statements such as this are becoming more and more popular and can be condensed to:

The faster society is changing, the more attention for the stability of history, the more popular preservation of cultural heritage.

\section{A philosophic point of view}

Based on Nietsche, F.,

The Use and Abuse of History (1874)

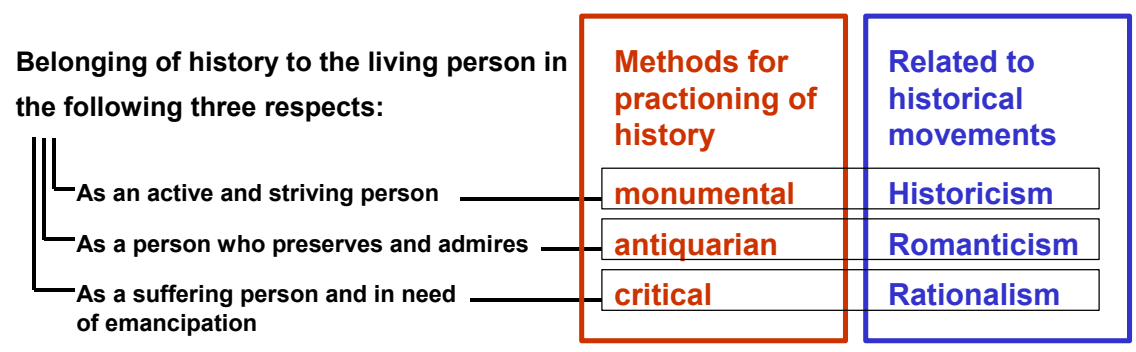

Figure 4: A philosophic point of view, based on Nietsche [2].

In the present situation the antiquarian point of view is dominant.

It is a time in which it becomes clear that the post war building production is not of a qualitative high level. Fast growth and high quality do not go together well. In the short period after the Second World War the rational point of view was dominant, related to urban development in Europe. Europe was aiming for a quantitative high building production, cities had to adapt to a growing mobility and a growing consumption. The transformation of many inner cities was initiated. Large scale traffic passages and the implementation of, for those days, large-scale retail concentrations were planned. Small scale and "a finely woven urban structure" were not valued then in the same way they are valued now. The reflection of our urban history was partly wiped out. Instead a reflection of recent history was created. The judgment of the present generation about those post-war interventions is not positive. According to Lowenthal [4], an explanation can at least partly be found in a common human characteristic.

"Any following generation is inclined to condemn the deeds of her immediate predecessors and at the same time honour the reputation of a past further back." [4]

The psychological need to preserve the past is concentrated, in the present societal context, on a bygone period that at least dates from before the Second World War. The urban remains of that time are to be found in the historic inner city. Those remains are part of a collection of historic fragments. The historic inner city in its present form represents not a specific, strictly bounded, historical period. The fragments represent the complete history of our urban development. A history book you can walk through. The most recent chapters in that book are considered not very interesting and even blameworthy. 


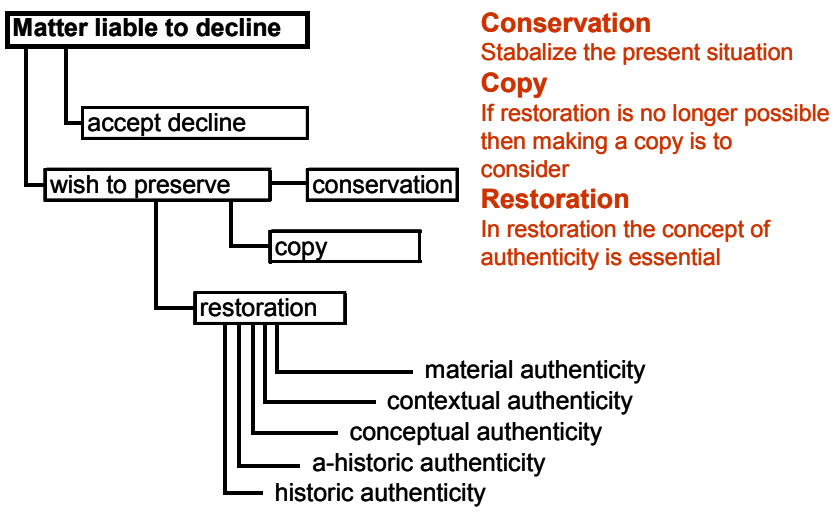

Figure 5: $\quad$ Forms of authenticity [5].
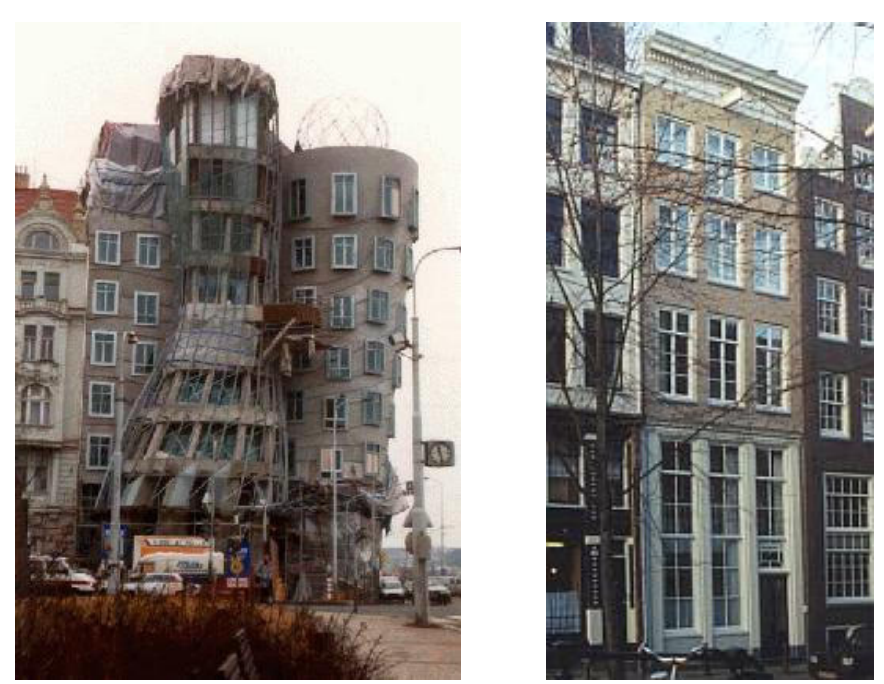

Figure 6: A new landmark in history and a look alike authentical.

\section{What to save, what to change?}

A large part of the historic inner cities of Europe have a protected status. The question "What to save?" is already answered by our predecessors. There is a strong trend with a broadly public support for preservation of historic values and cultural heritage. But what is cultural heritage?

The whole of our man made habitat belongs to our cultural heritage. If preservation is the only goal then any innovation is blocked. Selection is necessary.

The old inner city area is different from other city areas particularly on the point of small scale, finely woven urban structure and a high level of differentiation. That differentiation is expressed in a differentiated façade picture 
which demonstrates that the urban structure is a compilation of individual buildings. That differentiation is expressed in a strong mix of functions. Houses are mixed with different kind of business oriented buildings, or there is even a mix in the same building. You can read a long historic background by looking at the buildings. The maintenance activities and the modifications and innovations over time, have a differentiation in the technical state and the functionality as a result. The entrance and front door of all the buildings are different. The different floors are all different in height. The windows of the one floor are different from the windows of another floor. The subsidence of each building has given each window its own unique deviation of the straight position. These were a few examples of aspects on which differentiation can be specified. It also demonstrates that there is a high "differentiation density" in the historic inner cities.

The message therefore is: stick to the smallness of scale, do not destroy the finely woven urban structure that was made taking into account the pedestrian and the barrow.

\section{How to save it, how to change it?}

Even if we stick to smallness of scale and to the finely woven urban structure, the renovation of urban elements will be necessary every now and then. We then can make a choice between preservation, restoration, to copy or to create a modern urban element.

In creating a new urban element there are again choices to make. Do we choose a modern product of this time and make a new landmark in history. Or do we choose for a "look alike authentical". Figure 6 contains an example of both: two new buildings in the old urban structure. One a design of Gehry for the office of Nationale Nederlanden in Prague, the other a design for a house of Buro de Binnenstad in Amsterdam. One is an example of a new landmark in history, the other an example of a look alike authentica.

\section{References}

[1] Meurs, P., 2000, De moderne historische stad, Rotterdam, Nai uitgevers.

[2] Nietsche,F., 1874, Vom Nutzen und Nachteil der Historie fur das Leben, Eng. Editie, The Use and Abuse of History, 1957, Indianapolis, BobbsMerill.

[3] Kotkin, Joel, 1999, The future of the center: The core city in the new economy, Policy study no 264.

[4] Lowenthal, D., 1985, The past as a foreign country, London, Cambridge University Press.

[5] Ex,N., 1993, Zo goed als oud, De achterkant van het restaureren Amsterdam, Amber, ISBN 905093238 X.

[6] Graham, B., Modern Europe, place, culture and identity, Oxford university press, 2002.

[7] Nota Belvedere, 1999, Ministerie VROM, ISBN 9032276158. 